\title{
Thermal imaging and frequency analysis
}

\author{
by M. Lähdeniemi, A. Ekholm and O. Santamäki
}

Department of Information Technology, Tampere University of Technology, FIN-28600 PORI, Finland; Laboratory of Technical Physics, Satakunta Polytechnic, Pori Institute of Technology, FIN-28600 PORI, Finland

\begin{abstract}
IR based thermology and thermal images can be used in many industrial areas of predictive maintenance. In most cases these applications concentrate on taking single samples from interesting surface temperatures which means loss of possibility for long time data recording. The use of a simple image averaging method creates image data without periodic behavior of the object in interest.

There is a lot of interest to be able to measure wide area temperature profiles from a fast moving surface (e.g. in paper machine) with track velocities like $10-20 \mathrm{~m} / \mathrm{s}$. Normal low speed line scanners typically give scanning speed of $50 \mathrm{~Hz}$ which in this case corresponds to $20 \mathrm{~m} / \mathrm{s} / 50 \mathrm{~Hz}=40 \mathrm{~cm}$ resolution, and thus obtained resolution is not high enough. To have more accurate vision to the surface, IR camera line scanning with line scanning frequency of $8000 \mathrm{~Hz}$ was proposed to be the solution which would provide a resolution of $20 \mathrm{~m} / \mathrm{s} / 8000 \mathrm{~Hz}=0.25 \mathrm{~cm}$ between surface points.

It is well-known fact that all not desired frequencies in a paper transfer system disturb the uniform paper drying process, which in some cases is the basic reason for low quality coating or even broken paper line. The possibility to detect these drying problems with thermal image frequency analysis will give a new way to control the paper drying process, and this method can be utilized in many other similar industrial processes, too. With modern IR temperature scanning equipment it is possible to have information about the temperature distribution along moving surface and then by using the well established frequency data analysis, the error estimations can be calculated. The careful analysis of this new method is given in the presentation.
\end{abstract}

\section{Introduction}

The IR camera used in this experiment was Inframetrics Model 740 IR Imaging Radiometer. The spatial resolution of this camera is 194 elements horizontally (50\% SFR) and 240 vertically. The scanning rate is $7812 \mathrm{~Hz}$ horizontal and $50 \mathrm{~Hz}$ vertical. By using this kind of camera it is possible to detect frequencies up to $25 \mathrm{~Hz}$. The fast line scan mode can be used to get more accurate vision from the inspected surface.

When set to line scan mode, the vertical scan stops at the center position, and scans of the single line occur at approximately $125 \mu$ s intervals. This means a frequency of $8000 \mathrm{~Hz}$ which makes theoretically possible to detect frequencies up to $4000 \mathrm{~Hz}$. In practice the reasonable frequency limit is about $250 \mathrm{~Hz}$ achieved in laboratory tests which originates from PAL video image aspects and radiometer IR detectors dynamic properties. Temperature line scans can be recorded with normal VCR equipment for further analysis [1].

\section{Theoretical aspects}

The idea in Fourier transform is to convert data from time domain to frequency domain. All Fourier transforms can be reduced to the DDFT (discrete-to-discrete Fourier transform). Numerical computation of Fourier transform requires a finite list of numbers. This means that infinite signals need to be windowed and continuous-time signals sampled. When given a sampled discrete-time signal $x$ and a finite time axis $\{0, T, \ldots,(N-1) T\}$, the DDFT is defined as

$$
\hat{x}(k F)=T \sum_{n=0}^{N-1} x(n T) e^{-j k n / N}, \mathbf{k} \in\{0,1, \ldots \mathrm{N}-1\}
$$


The direct computation of DDFT is very time-consuming, but there exists a very efficient algorithm for computing the DDFT, called Fast Fourier Transform (FFT). The most widely used method for computing FFT is Cooley-Turkey radix 2 FFT. The principle of this method, like all other FFT-methods, is to convert a single numerically intensive computation to repeated easy computations.

The goal of this experiment is to develop a system that detects frequencies from the studied surface. This is done by using fast line scan mode to get IR data accurate enough and then using FFT for transferring data from time domain to frequency domain. The final step is to develop recognition algorithms for detecting of frequencies. The implementation phase was to create image processing software for data capture and analysis with fulfilled speed properties for continuous spectral logging.

\section{Experiments}

In an earlier paper, a preliminary approach was made by using stroboscope light tests which gave encouraging results for further development [5]. In this phase it proved out, that it was possible to adjust normal video image synchronizing with image sampling rate up to highest Nyquist frequency of $500 \mathrm{~Hz}$ meaning frequency detecting of $250 \mathrm{~Hz}$ signal. Finally test material for field evaluation was collected from the local paper industry with prior knowledge about existing frequency disturbance causing occasional defects to the final product.

\section{Analysis}

Earlier, our algorithms were tested successfully with stroboscope lamp, CCD-camera, thermal camera and thermal vibrator [5]. Frequency analysis was done by using several sampling frequencies from $50 \mathrm{~Hz}$ to $500 \mathrm{~Hz}$. Low sample frequency gives a more accurate frequency domain chart for lower frequencies and high sample frequency gives a wideranging chart. Both types were needed because of the need to find out - if possible - the existing frequency disturbance accurately enough and to check out that it is also possible to find it by using high sample frequencies. This was, at the same time, the method to test our system capabilities.

Figure 1 shows the frequency domain analysis of a rolling paper surface, sample frequency is $100 \mathrm{~Hz}$. By using frequency analysis it is possible to see at least one frequency, that has diverging magnitude, about $43 \mathrm{~Hz}$. It is also possible to see a minor alteration at the frequency of $37 \mathrm{~Hz}$. This data was collected from the dry end of the paper machine.

Figure 2 is a frequency domain chart for the same spot reported in figure 1, but the sample frequency is $500 \mathrm{~Hz}$. Again it is possible to point out the frequency of $43 \mathrm{~Hz}$. Data was collected from PAL video signal, which means with a disturbance at $50 \mathrm{~Hz}$ and its harmonic frequencies. This can be seen in the chart : $50,100,150$ and $200 \mathrm{~Hz}$. This widerange chart describes the distribution of frequencies. Thermal vibration is concentrated on frequencies lower than $100 \mathrm{~Hz}$.

Diverging magnitudes can be found also in the beginning of the paper machine (wet end). Figure 3 shows that it is still possible to detect the magnitude of $43 \mathrm{~Hz}$, but it is not decisive any more. Now the magnitude of $37 \mathrm{~Hz}$ is more dominatsing. When looking at the magnitude, it can be seen that the vibration is much weaker at the beginning of the paper machine than at its end.

\section{Conclusions}

The result of this paper shows how IR measured temperature from a fast, steadily moving surface can be used to detect frequencies in drying and coating processes. In the area of paper industry there will be a challenge to find out the significance of these frequencies and the usability of this easily performed measurement method in preventive maintenance. At the same time new applications will be sought from various industrial areas where frequencies are important indicators of process quality. 


\section{Acknowledgments}

This work was financially supported by Satakunta Foundation of High Technology.

\section{REFERENCES}

[1] LÄHDENIEMI (M.) and MÄENPÄÄ (M.). - Heat images in maintenance and production, Electricity and Electronics, Vol. 62, 1989, p. 18-20

[2] LÄHDENIEMI (M.) and EKHOLM (A.). - Industrial maintenance with infrared thermology, Quantitative Infrared Thermography, Balageas, Busse, Carlomagno, Europeennes Thermique et Industrie ed., Paris, France, 1993.

[3] TAKALA (J.), LÄHDENIEMI (M.) and TANTTU (J.T.). - Infrared Monitoring of Plant Damages and Herbivore Invasions, Thermosense XVII: An Intemational Conference on Thermal Sensing and Imaging Diagnostic Applications, SPIE Proc. 2473, Orlando, April 1995, p. 358 - 359

[4] LÄHDENIEMI (M.), EKHOLM (A.), KOPPEL (T.) and LIIV (U.). - Unsteady Flow Investigation by Infrared and Thermoanemometer Techniques, Proceedings of the 4th Scandinavian Intemational Conference on Fluid Power, Tampere, September 1995, p. 432 441

[5] LÄHDENIEMI (M.), EKHOLM (A.) and SANTAMÄKI (O.). - IR Frequency analysis in paper industry, Thermosense XVIII: An Intermational Conference on Thermal Sensing and Imaging Diagnostic Applications, SPIE Proc. 2766, Orlando, April 1996, p. 2 - 4

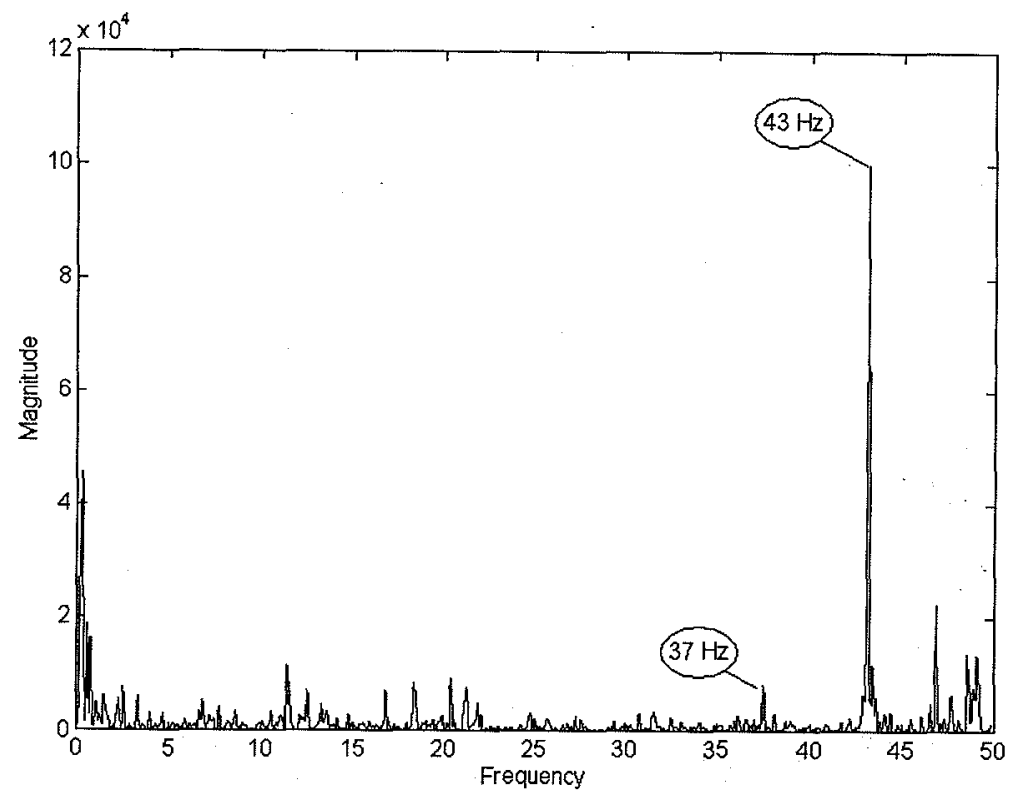

Fig. 1. Frequency analysis, dry end of paper machine 
http://dx.doi.org/10.21611/qirt.1996.046

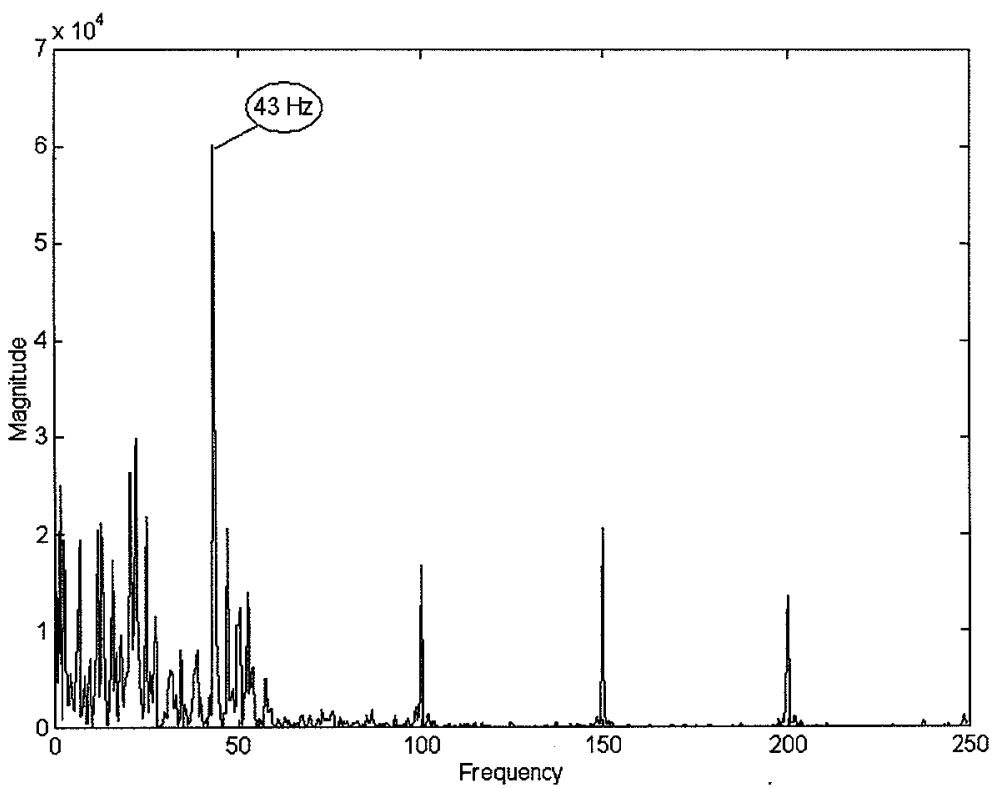

Fig. 2. Frequency analysis, dry end of paper machine, sample freq. $500 \mathrm{~Hz}$

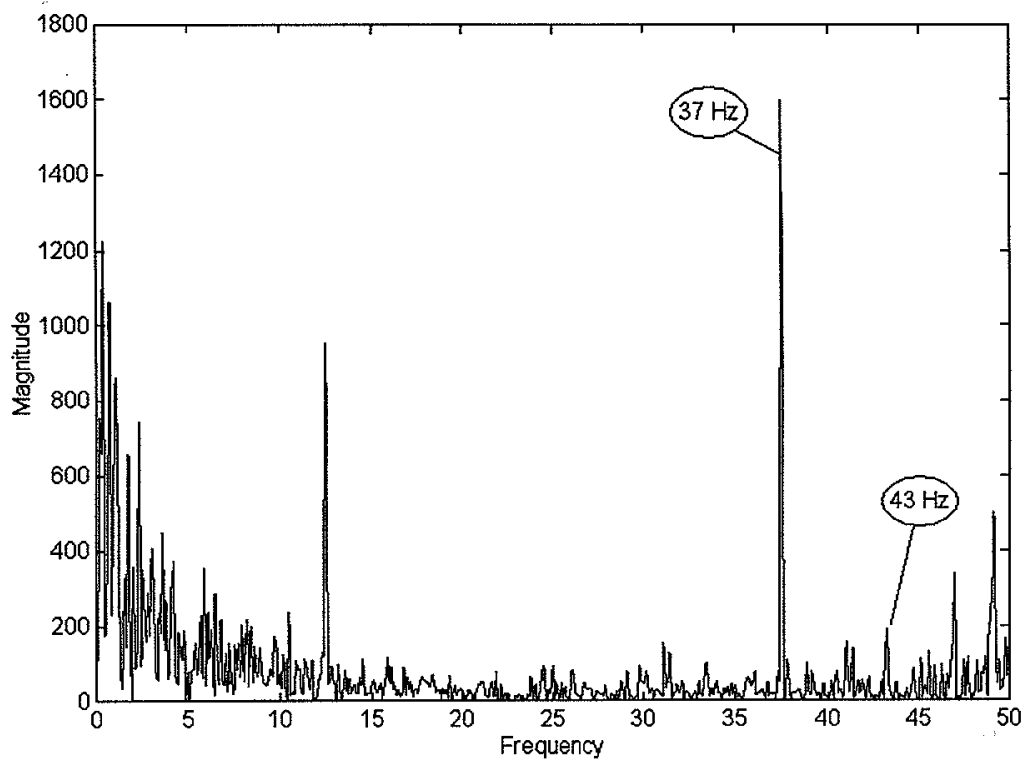

Fig. 3. Frequency analysis, wet end of paper machine 